\title{
Thermal Analysis of Solar Protection on Windows in Tropical Areas
}

\section{Analisis Termal Proteksi Surya Pada Jendela Bangunan di Daerah Tropis}

Fadhilla Azherda ${ }^{1 *}$, Remon Lapisa ${ }^{1}$, Waskito ${ }^{1,}$ Hasanuddin $^{1}$

\begin{abstract}
Thermal comfort is one element of comfort that is very important, because it concerns the condition of the room temperature. Where the cool temperature in the room is a condition of thermal comfort of a building, besides indoor lighting also affects the comfort of the room. The building window is one of the factors that affects the thermal comfort of the building, therefore, it is necessary to find the solution for the heat absorption that occurs through the glass window not directly into the building. This research aims to analyze the solar protection on the windows of the building on the teropical climate, in the windows of paired Building solar protection (Solar Shading) that can be variated tilt angle. which uses a variation of tilt angles of $0^{\circ}(-), 45^{\circ}(/)$, and $90^{\circ}(/)$ with the aim of obtaining indoor thermal comfort as well as indoor lighting.
\end{abstract}

\section{Keywords}

Solar protection, thermal comfort, lighting, climate.

\begin{abstract}
Abstrak
Kenyamanan termal merupakan salah satu unsur kenyamanan yang sangat penting, karena menyangkut kondisi suhu ruangan. Dimana temperature dalam ruangan yang sejuk adalah syarat kenyamanan termal suatu bangunan, selain itu pencahayaan dalam ruangan juga mempengaruhi kenyamana dalam ruangan. Jendela bangunan merupakan salah satu faktor yang mempengaruhi kenyamanan termal pada bangunan, Oleh karena itu perlu dicarikan solusi agar penyerapan panas yang terjadi melalui jendela kaca tidak lansung masuk kedalam bangunan. Penelitian ini bertujuan untuk menganalisis proteksi surya pada jendela bangunan pada iklim teropis, pada jendela bangunan dipasangkan proteksi surya (Solar Shading) yang dapat divariasikan sudut kemiringan. dimana menggunakan variasi sudut kemiringan $0^{\circ}(-), 45^{\circ}(/)$, dan $90^{\circ}(\mid)$ dengan tujuan mendapatkan kenyamanan termal dalam ruangan dan juga pencahayaan dalam ruangan.
\end{abstract}

\section{Kata Kunci}

Proteksi Surya, Kenyamanan Termal, Pencahayaan, Iklim.

${ }^{1}$ Pendidikan Teknik Mesin, Universitas Negeri Padang

jl.Prof. Dr. Hamka, Kel. Air Tawar, Padang, Sumatera Barat, Kode Pos: 25132

*azherdafadhilla@gmail.com

Submitted : February 10, 2020. Accepted : March 13, 2020. Published : May 01, 2020. 


\section{PENDAHULUAN}

Dampak kerusakan lingkungan yang tengah dihadapi telah memunculkan konsep berkelanjutan yang mempengaruhi hampir semua aspek kehidupan. Dampak kerusakan lingkungan yang paling popular adalah pemanasan global yang disebabkan oleh gas rumah kaca (GRK), salah satunya adalah gas karbon (CO2), hasil konversi dan penggunaan energi sebagai kebutuhan vital dari kehidupan modern. Demikian pula energi yang dibutuhkan oleh sektor bangunan, terutama kebutuhannya akan energi listrik. Kebutuhan energi listrik pada sektor bangunan ternyata paling tinggi dari pada sektor lainnya, seperti transportasi, industri, dll.

Di Indonesia, bangunan gedung perkantoran membutuhkan listrik hingga 210-285 $\mathrm{kWh} / \mathrm{m} 2$ setiap tahun data statistik bidang kelistrikan dan energi pada tahun 2011 (sumber: BPS 2011) bahwa sektor bangunan membutuhkan hingga 50\% total pengeluaran energi di Indonesia serta menghasilkan emisi GRK hingga 30\%. Menurut (Litbang KOMPAS/Kompas: 2013) Menyatakan, anggaran belanja negara tersedot banyak pada sektor listrik dan BBM pada APBN-P 2013 hingga 299,8 triliun rupiah dan masih menganggarkan sebesar 282, 1 triliun rupiah untuk APBN 2014. Untuk itu, maka perlu dilakukan usaha penghematan energi listrik agar ketersediaan sumber daya alam dan kerusakan lingkungan dapat teratasi demi keberlangsungan hidup di masa depan sesuai dengan Konsep Berkelanjutan

Menurut (Kerr, 2008) Bangunan adalah salah satu pengkonsumsi energi terbesar, World Green Building Council menyebutkan bahwa sektor konstruksi menyerap 30-40\% total energy dunia. Oleh karenanya, penerapan konsep hemat energi dari sektor bangunan akan dapat memberikan efek signifikan pada keberlanjutan ketersediaan energi. Salah satu upaya penghematan energi pada bangunan adalah dengan optimalisasi desain untuk penggunaan sumber daya alam, termasuk di dalamnya pencahayaan.

Studi pada bangunan kantor di hawaii menyebutkan bahwa 27\% dari total konsumsi energi bangunan tergunakan untuk pencahayaan buatan yang banyak mengkonsumsi energi listrik yang mengakibatkan semakin meningkatnya polusi gas rumah kaca yang di hasilkan, oleh karena itu dengan pengoptimalisasian penggunaan pencahayaan alami membantu mengurangi konsumsi dari energi listrik yang dituhkaan, maka persentase tersebut dapat ditekan.

Masalah yang kemudian muncul adalah tentang kenyamanan visual yang ditimbulkan oleh pencahayaan alami dalam ruang. Pengguna bangunan pada dasarnya menghendaki adanya pencahayaan alami. Sebuah review pada reaksi pengguna terhadap lingkungan dalam bangunan menyatakan bahwa tersedianya pencahayaan alami secara optimal sangat diinginkan karena memenuhi dua kebutuhan dasar manusia: kebutuhan visual untuk melihat baik bidang kerja maupun ruangan dan untuk mengalami stimulasi lingkungan dari efek pencahayaan tersebut (Boyce, 1998 dalam IEA, 2000).

Sebuah bangunan mempunyai nilai estetis, berfungsi tujuan bangunan tersebut dirancang, memberikan rasa 'aman' (dari gangguan alam dan manusia/makhluk lain), serta memberikan 'kenyamanan'. Berada di dalam bangunan agar tidak merasa kepanasan, tidak merasa kegelapan akibat kurangnya cahaya, dan tidak merasakan bising yang berlebihan. Setiap bangunan diharapkan dapat memberikan kenyamanan termal dan visual.

Kenyamanan termal merupakan salah satu unsur kenyamanan yang sangat penting, karena menyangkut kondisi suhu ruangan yang nyaman. Seperti diketahui, manusia merasakan panas atau dingin merupakan wujud dari sensor perasa pada kulit terhadap kondisi suhu di sekitarnya. Sensor perasa berperan menyampaikan informasi rangsangan kepada otak, dimana otak akan memberikan perintah kepada bagian-bagian tubuh tertentu agar melakukan antisipasi untuk mempertahankan suhu sekitar $37^{\circ} \mathrm{C}$. Hal ini diperlukan organ tubuh agar dapat menjalankan fungsinya secara baik. Uraian di atas penulis tertarik untuk 
melakukan penelitian untuk meningkatkan kenyamanan termal di dalam ruangan melalui modifikasi material Jendela untuk mengurangi transfer panas ke dalam ruangan.

\section{METODE PENELITIAN}

Penelitian ini dilakukan untuk mengetahui pengaruh sinar matahari terhadap suhu $\left({ }^{\circ} \mathrm{C}\right)$ dan tingkat pencahayaan (lux) pada rumah. Pengukuran dilakukan pada dua busah prototipe dengan panjang $80 \mathrm{~cm}$, lebar $60 \mathrm{~cm}$, dan tinggi $50 \mathrm{~cm}$. pada kaca jendela bangunan di pasangkan penutup radiasi matahari (solar shading) yang di variasikan dengan beberapa sudut kemiringan berbeda yaitu $0^{\circ}(-), 45^{\circ}(/)$, dan $90^{\circ}(\mid)$ guna mengetahui kenyamanan suhu dan pencahaayaan dalam ruangan. Dalam penelitian ini salah satu banguna rumah di pasang penutup radiasi matahari pada jendela. Data yang akan diambil berupa suhu $\left({ }^{\circ} \mathrm{C}\right)$ dalam ruangan dan tingkat pencahayaan (lux) pada ruangan protipe.

Dalam pengambilan data prototipe di tempatkan di halaman terbuka kelompok dasa wisma beringin RT. 05 RW. 04, Kel. Ulakkarang Kec.Padang utara jalan paus No.10 yang terkena paparan matahari langsung. Pengambilan data dilakukan selama 9 jam dengan rentang waktu setiap per 10 menit, penelitian ini berlangsung selama 3 hari berturut-turut di bulan Januari. Pada saat pengambilan data masing-masing prototipe dipasangkan satu alat thermometer yang terdiri dari satu sensor termokopel.

HASIL DAN PEMBAHASAN

\section{Perbandingan suhu ruang utama prototipe pada hari pertama dengan dan tanpa protektor surya.}

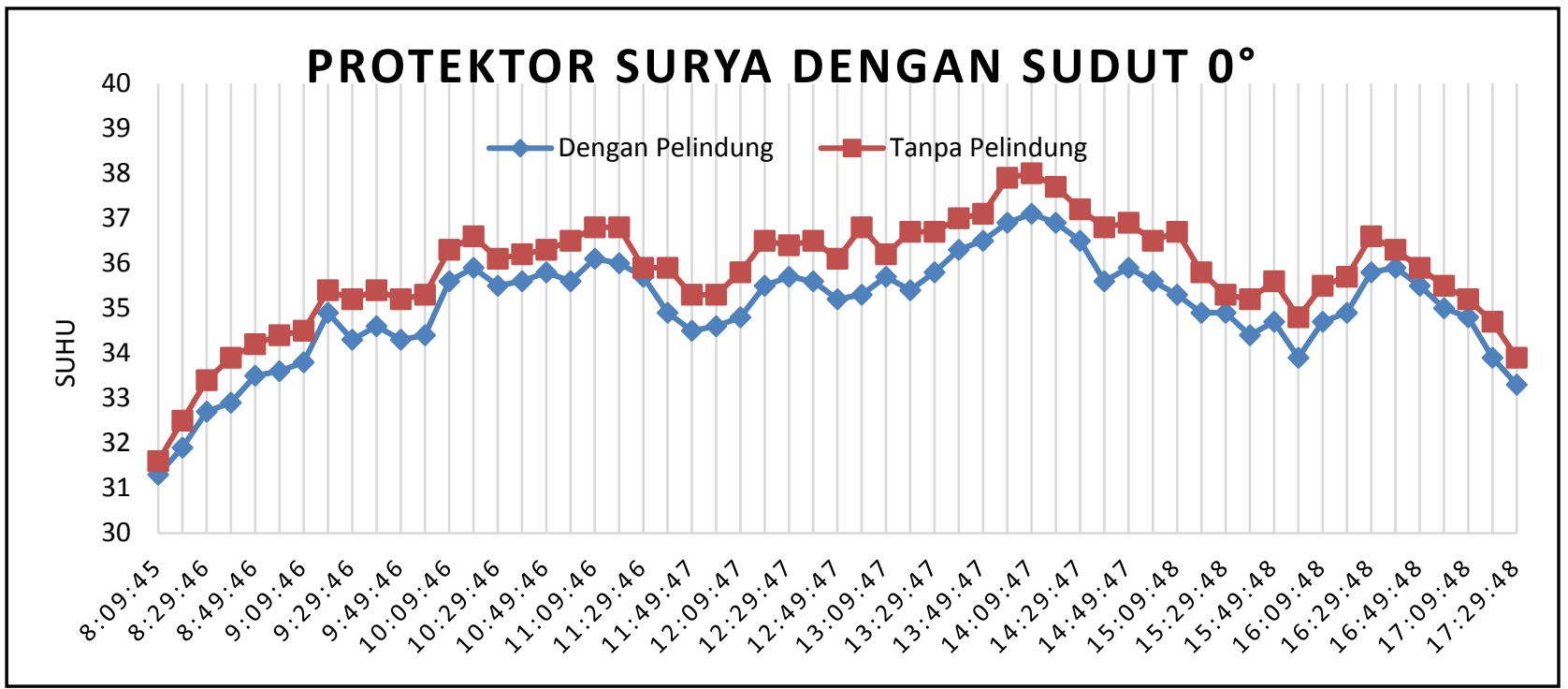

Grafik.1. ruang utama prototipe dengan dan tanpa protektor surya.

Dari hasil pengujian pada hari pertama didapatkan pada saat jam 08:29 suhu dalam ruanga mengalami peningkatan secara berkala hingga jam 11:29 suhu mengalami kenaikan pada saat jam tersebut. suhu dalam ruangan tertinggi dialami oleh rumah yang tidak diberi pelindung karena pancaran sinar matahari langsung masuk ke dalam ruang tanpa adanya hambatan. Pada saat jam 11:399 suhu dalam ruangan mengalami penurunan secara berkala, hal ini disebabkan karena pada saat itu panas matahari terhalang oleh cuaca yang berubah secara tiba-tiba, Namun pada saat jam tersebut suhu yang diterima pada bangunan yang di pasangkan pelindung lebih rendah dibandingkan dengan bangunan yang tidak di berikan pelindung. 
Hal ini disebabkan karena panas matahari yang diterima oleh bangunan dengan pelindung dipantulkan dan tidak langsung masuk kedalam ruangan sedangkan bangunan yang tidak diberi pelindung pancaran sinar matahari yang masuk tidak terdapat hambatan sehingga mengakibatkan panas yang masuk kedalam ruangan secara maksimal.

Pada saat jam 14:19-14:29 suhu dalam ruangan mulai mengalami peningkatan secara maksimal karena pancaran panas matahari, Dimana suhu bangunan dengan pelindung lebih rendah dari pada bangunan yang tanpa pelindung. Dari hasil pengujian pada siang hari didapat bahwa kondisi suhu dalam ruangan tanpa diberi pelindung pada bagian kaca jendela lebih panas dibandingkan dengan banguna yang di berikan pelindung dengan kemiringan $0^{\circ}$. Hal ini dapat terjadi karena perlindung yang di pasang pada salah satu prototipe berfungsi memantulkan pancaran panas matahari langsung yang masuk kedalam ruangan bangunan.

Selisih rata-rata suhu antara bangunan yang diberi pelindung dengan kemiringan $0^{\circ}$ dan banguna yang tidak diberi pelindung adalah $0.77^{\circ} \mathrm{C}$. Jadi dapat disimpulkan bahwa proteksi surya dapat menurunkan suhu sebesar $0.77^{\circ} \mathrm{C}$ di banding dengan rumah tanpa pelindung.

\section{Perbandingan suhu ruang utama prototipe pada hari Kedua dengan dan tanpa protektor surya.}

\section{protektor surya dengan sudut $45^{\circ}$}

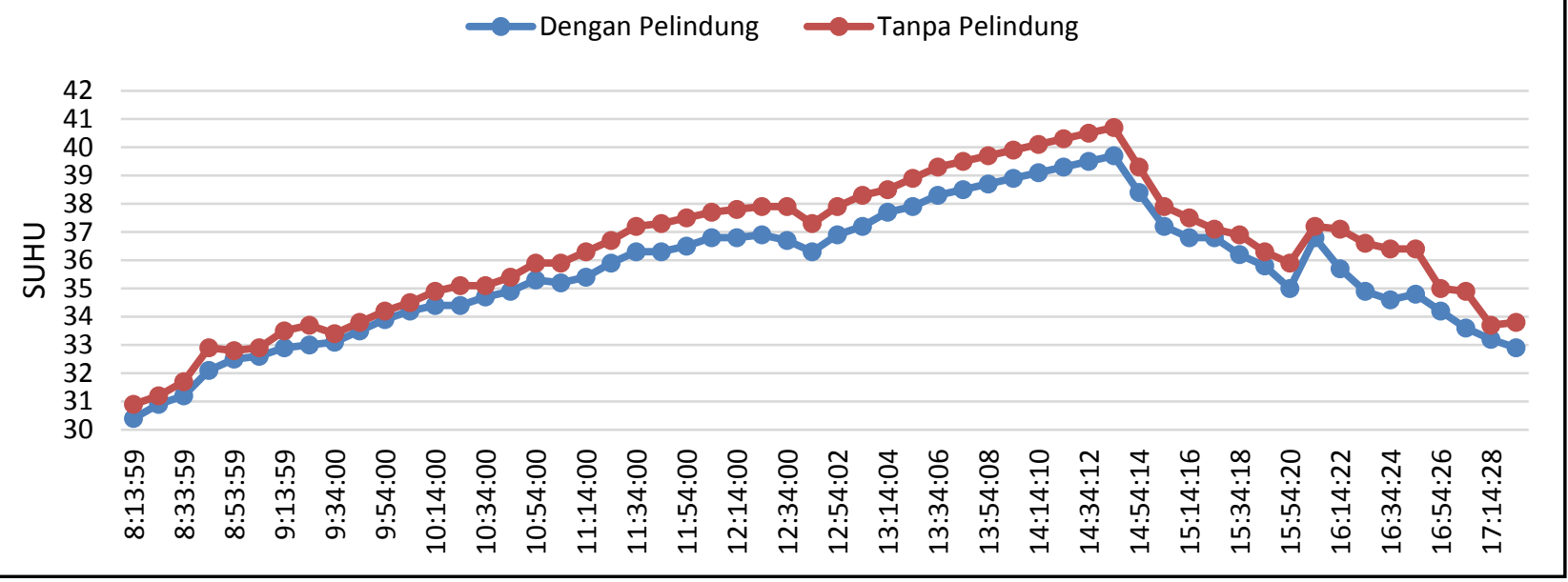

Grafik.2. ruang utama prototipe dengan dan tanpa protektor surya.

Dari hasil pengujian hari kedua pada pagi hari didapatkan bahwa pada saat jam 10:24 suhu dalam ruanga material mengalami peningkatan suhu secara berkala, pada saat jam tersebut suhu dalam ruangan tertinggi dialami oleh rumah yang tidak diberi pelindung karena pancaran sinar matahari langsung masuk ke dalam ruangan tanpa adanya hambatan. Pada saat jam 12:04-14:54 suhu dalam ruangan mengalami kenaikan suhu secara drastis, hal ini disebabkan karena pada saat itu matahari memancarakan sinarnya dengan maksimal sehingga panas yang diterima begitu tinggi, Namun pada saat jam tersebut suhu yang diterima pada bangunan yang di pasangkan pelindung lebih rendah dibandingkan dengan bangunan yang tidak di berikan pelindung.

Hal ini disebabkan karena pancaran sinar matahari yang diterima oleh bangunan dengan pelindung dipantulkan dan tidak langsung masuk kedalam ruangan sedangkan bangunan yang tidak diberi pelindung pancaran sinar matahari yang masuk tidak terdapat hambatan sehingga mengakibatkan panas yang masuk kedalam ruangan secara maksimal.

Pada saat jam 15:04-17:04 suhu dalam ruangn mulai mengalami penurunan karena pancaran panas matahari mulai berkurang, hal ini disebabkan cuaca yang berubah - ubah. 
Dimana suhu bangunan dengan pelindung lebih rendah dari pada bangunan yang tanpa pelindung

Dari hasil pengujian pada siang hari didapat bahwa kondisi suhu dalam ruangan tanpa diberi pelindung pada bagian kaca jendela lebih panas dibandingkan dengan banguna yang diberikan pelindung dengan kemiringan $45^{\circ}$. Hal ini dapat terjadi karena perlindung yang dipasang pada salah satu prototipe berfungsi memantulkan pancaran panas matahari lansung yang masuk kedalam ruangan bangunan.

Selisih rata-rata suhu antara bangunan yang di beri pelindung dengan kemiringan $45^{\circ}$ dan bangunan yang tidak diberi pelindung adalah $0.80^{\circ} \mathrm{C}$. Jadi dapat disimpulkan bahwa protektor surya dapat menurunkan suhu sebesar $0.80^{\circ} \mathrm{C}$ dibandingkan dengan rumah yang tanpa diberi pelindung. Sebab dapat memantulkan pancaran panas matahari maksimal yang masuk dalam bangunan.

\section{Perbandingan suhu ruang utama prototipe pada hari ketigaa dengan dan tanpa protektor surya.}

\section{protektor surya dengan sudut $90^{\circ}$}

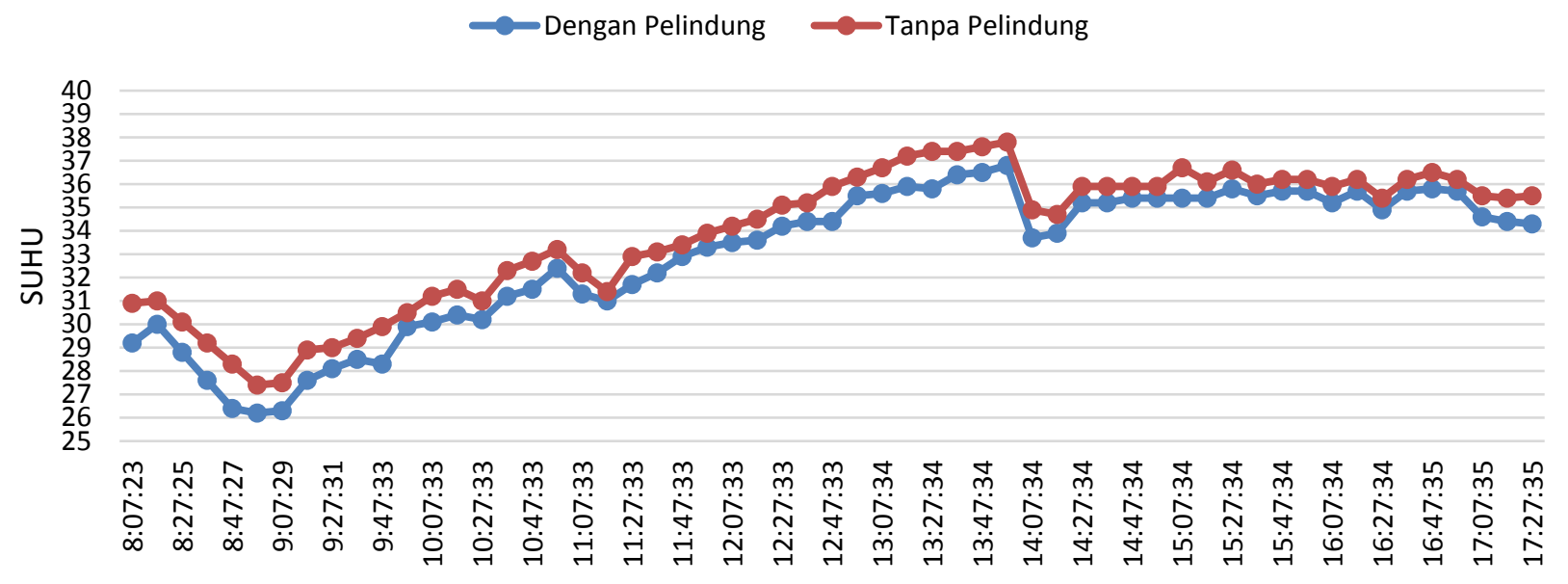

Grafik.3. ruang utama prototipe dengan dan tanpa protektor surya.

Dari hasil pengujian pada hari ketiga didapatkan pada jam 08:017-09-07 suhu dalam ruanga terbilang rendah disebabkan oleh cuaca yang berubah-ubah. Peningkatan suhu secara berkala terjadi pada jam 09:17 suhu mengalami kenaikan berkala, pada saat jam tersebut suhu dalam ruangan tinggi dialami oleh rumah yang tidak diberi pelindung karena pancaran panas dari sinar matahari langsung masuk ke dalam ruang tanpa adanya hambatan. Pada saat jam 10:57 suhu dalam ruangan mengalami penurunan kembali, dimana bangunan rumah yang diberikan pelindung pada jendela kacanyapun mengalami penurunan. panas matahari mengalami kenaikan maksimal pada jam 13:57. Namun pada saat jam tersebut suhu yang diterima pada bangunan yang di pasangkan pelindung lebih rendah dibandingkan dengan bangunan yang tidak diberikan pelindung.

Hal ini disebabkan karena pancaran panas dari sinar matahari yang diterima oleh bangunan dengan pelindung dapat dipantulkan dan tidak langsung masuk kedalam ruangan sedangkan bangunan yang tidak diberi pelindung pancaran sinar matahari yang masuk tidak terdapat hambatan sehingga mengakibatkan panas yang masuk kedalam ruangan secara maksimal.

Pada saat jam 14:07-14:17 suhu dalam ruangan mulai mengalami penurunan secara drastis karena pancaran panas matahari mulai berkurang diakibatkan cuaca yang berubah- 
ubah, Namun suhu pada bangunan dengan pelindung tetap lebih lebih rendah dari pada bangunan yang tanpa pelindung. Dan pada jam-jam berikutunya suhu dalam ruangan kembali naik secara bertahap.

Dari hasil pengujian pada siang hari didapat bahwa kondisi suhu dalam ruangna tanpa diberi pelindung pada bagian kaca jendela lebih panas dibandingkan dengan banguna yang di berikan pelindung dengan kemiringan $90^{\circ}$. Hal ini dapat terjadi karena perlindung yang di pasang pada salah satu prototipe berfungsi memantulkan pancaran panas matahari langsung yang masuk kedalam ruangan bangunan.

Selisih suhu antara banguna yang di beri pelindung dengan kemiringan $180^{\circ}$ dan banguna yang tidak diberi pelindung $0.94^{\circ} \mathrm{C}$. Jadi dapat disimpulkan bahwa diantara dua banguna tersebut yang bagus dalam menahan panas pada siang hari adalah bangunan yang dipasang pelindung pada jendela kaca, sebab dapat memantulkan pancaran panas matahari maksimal yang masuk dalam bangunan

Perbandingan pencahayaan (lux) dalam ruang utama prototipe pada hari pertama sampai hari ketiga dengan dan tanpa protektor surya, pada variasi sudut $0^{\circ}(-), 45^{\circ}(/)$, dan $90^{\circ}(\mid)$.

\section{INTENSITAS PENCAHAYAAN (LUX) PADA BANGUNAN RUMAH}

\begin{tabular}{|c|c|c|c|c|c|}
\hline \multirow[t]{2}{*}{$\begin{array}{r}1400 \\
1250 \\
1100 \\
950 \\
800 \\
650 \\
500 \\
350 \\
200\end{array}$} & & & & 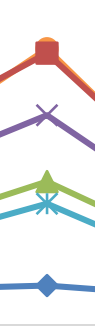 & \\
\hline & $8: 00$ & $10: 00$ & $12: 00$ & $14: 00$ & $16: 00$ \\
\hline$\simeq$ Dengan Pelindung $\left(0^{\circ}\right)$ & 50 & 250 & 350 & 700 & 200 \\
\hline *Tanpa Pelindung & 60 & 280 & 560 & 1000 & 270 \\
\hline *-Dengan Pelindung $\left(45^{\circ}\right)$ & 60 & 220 & 300 & 600 & 140 \\
\hline - Tanpa Pelindung & 80 & 290 & 580 & 1300 & 250 \\
\hline —Dengan Pelindung $\left(90^{\circ}\right)$ & 50 & 100 & 200 & 230 & 150 \\
\hline$\longrightarrow$-Tanpa Pelindung & 100 & 230 & 700 & 1280 & 290 \\
\hline
\end{tabular}

Grafik.4. ruang utama prototipe dengan dan tanpa protektor surya pada variasi sudut $0^{\circ}(-), 45^{\circ}(/)$, dan $90^{\circ}(1)$

Dari hasil pengujian pada hari pertama hingga hari ketiga didapatkan pada jam 08:00 intensitas lux dalam ruanga terbilang rendah. Peningkatan pancaran sinar matahari secara berkala terjadi pada jam 10:00, pada saat jam tersebut sinar matahari yang masuk ke dalam ruangan tinggi dialami oleh rumah yang tidak diberi pelindung karena pancaran dari sinar matahari langsung masuk ke dalam ruang tanpa adanya hambatan. Pada saat jam 14:00 suhu dalam ruangan mengalami kenaikan secara maksimal, dimana bangunan rumah yang di berikan pelindung pada jendela kaca mampu memantulkan pancara sinar matahari yang masuk sedangkan rumah yang tidak dipasang pelindung pada jendela kaca, Pancaran sinar matahari (lux) yang masuk terhitung tinggi.

Namun pada saat jam 16:00 pencahayaan (lux) yang diterima mulai turun, Hal ini disebabkan karena pancaran dari sinar matahari yang diterima oleh bangunan mulai 
berkurang, akan tetapi bangunan yang dipasangkan pelindung pada kaca jendela tetap lebih kecil nilai (lux) yang diterima dari pada bangunan yang tidak di pasangkan proteksi surya. Hal ini dapat terjadi karena perlindung yang di pasang pada salah satu prototipe berfungsi memantulkan pancaran panas matahari langsung yang masuk kedalam ruangan bangunan. Dari grafik diatas variasi sudut kemiringan mempengaruhi jumlah besar atau kecil nilai dari pencahaayaan (lux) yang diterima oleh bangunan .

Jadi dapat disimpulkan bahwa diantara dua banguna tersebut yang bagus dalam menahan panas pada siang hari adalah bangunan yang di pasang pelindung pada jendela kaca, sebab dapat memantulkan pancaran sinar matahari maksimal yang masuk dalam bangunan.mengalami penurunan maka suhu kamar juga ikut mengalami penurunan suhu.

Perbandingan suhu ruang dan pencahayaan (lux) pada ruangan utama prototipe hari pertama hingga hari ketiga dengan dan tanpa protektor surya digunakan tiga variasi sudut $90^{\circ}(\mid), 45^{\circ}(/)$, dan $0^{\circ}(-)$. Dimana data pembanding diambil dari jam 10:00, 12:00 dan 14:00.

Perbandingan suhu dan pencahayaan pada jam 10:00. Pengambilan data dilakuka pada jam yang sama dan hari yang berbeda.

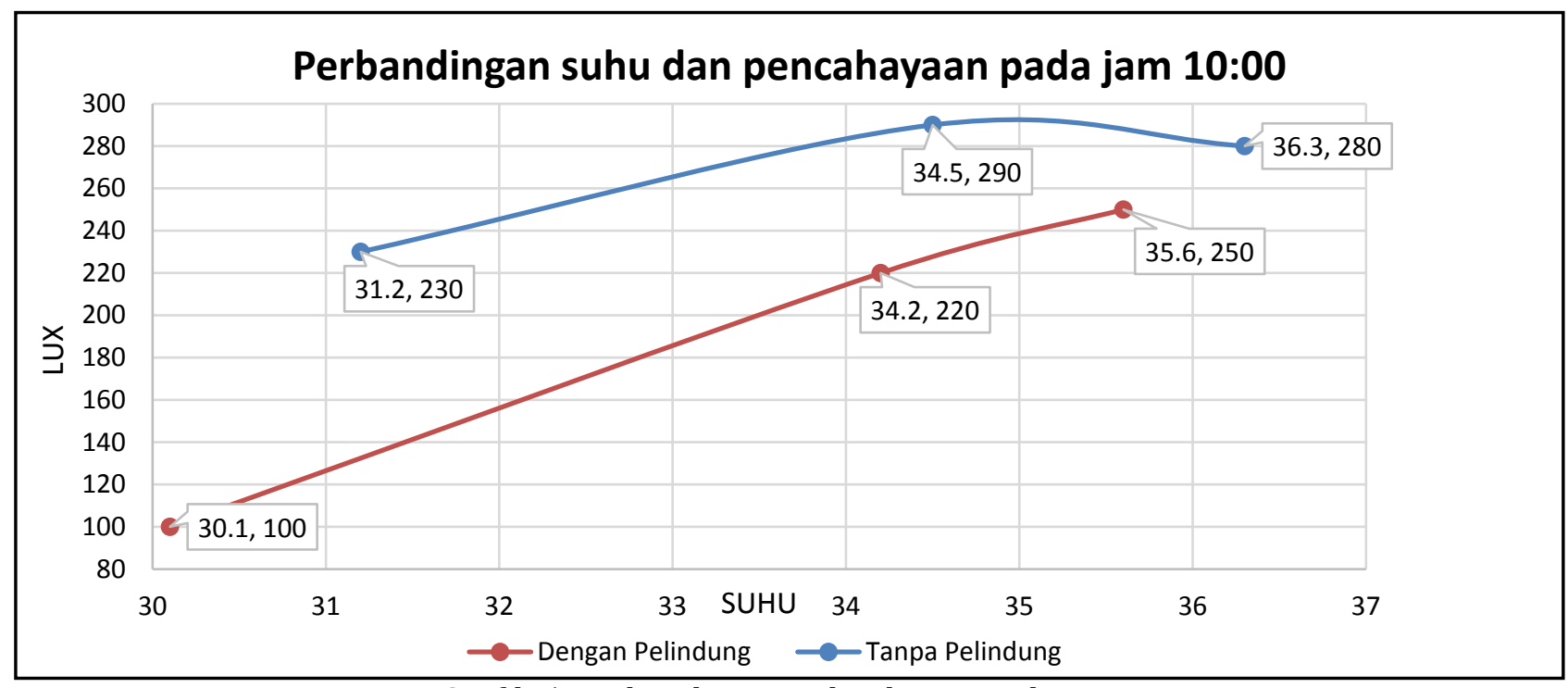

Grafik.5. Perbandingan suhu dan pencahayaan

Pada grafik diatas dapat digambarkan optimasi sudut kemiringan proteksi surya pada sudut $90^{\circ}(\mid), 45^{\circ}(/)$, dan $0^{\circ}(-)$. Berdasarkan temperatur suhu yang diambil pada jam 10.00. Lux yang didapat terpengaruh dari pelindung yang diberikan pada salah satu jendela kaca prototipe. Pada grafik diatas di dapatkan pada bangunan prototipe yang tidak diberikan pelindung memiliki nilai yang tinggi dibandingkan dengan bangunan prototipe yang di pasangkan pelindung pada bagian kaca jendela. Pada grafik di atas suhu yang paling tinggi ada pada sudut variasi kemiringan $0^{\circ}(-)$, dimana pada kedua prototipe sama-sama memiliki nilai lebih tinggi dibandiingkan dengan kedua sudut variasi pada jam yang sama dan nilai pencahayaan yang paling tinggi juga dialami sudut variasi kemiringan $0^{\circ}(-)$.

Sehingga bangunan yang dipasangkan pelindung pada kaca jendela lebih baik dalam meminimalkan suhu dan juga Penmcahayaan yang masuk kedalam bangunan prototipe. Dibandingkan dengan bangunan yang tanpa di beri pelindung. Pelindung yang dipasangkan pada jendela kaca prototipe terjadi selisih suhu dan penahayaan yang signifikan kerena 
pelindung yang di pasang pada kaca jendela dengan sudut variasi $90^{\circ}(\mid), 45^{\circ}(/)$, dan $0^{\circ}(-)$ dapat memantulkan pancaran matahari lansung yang akan masuk kedalam ruangan.

Maka nilai suhu dan pencahayaan yang didapatkan dari kedua protoripe lebihtinggi terutama pada rumah yang tidak dipasangkan proteksi surya pada jendela kaca prototipe. Dimana pelindung yang dipasang berfungsi memantulpan sinar matahari yang masuk kedalam bangunan, sehinnga suhu dan pencahayaan yang masuk ke dalam banguna prototipe lebih rendah dibandingkan dengan yang tidak di pasangkan proteksi surya.

Jadi dari ketiga variasi sudut pada grafik diatas diambil pada jam 10:00 yang lebih baik dalam menahan suhu panas dan sinar matahari yang masuk kedalam ruangan secara langsung adalah proteksi surya dengan variasi sudut $45^{\circ}$ karena suhu dalam ruangan prototipe yang dipasangkan pelindung kaca jendelanya jauh lebih biak dari pada prototipe bangunan yang tidak diberi pelindung pada jendela kaca.

Selain itu juga mampu memantulakan pancaran sinar matahari yang masuk secara langsung kedalam ruangan tanpa mengurani kenyaman dalam beraktifitas dalam ruangan karena pencahayaan yang dihasilkan terbilang baik dalam melakukan kegiatan dalam ruangan pada pagui hari, tanpa menggunakan pencahayaan buatan tambahan dari lampu.

Perbandingan suhu dan pencahayaan pada jam 12:00 Pengambilan data dilakuka pada jam yang sama dan hari yang berbeda.

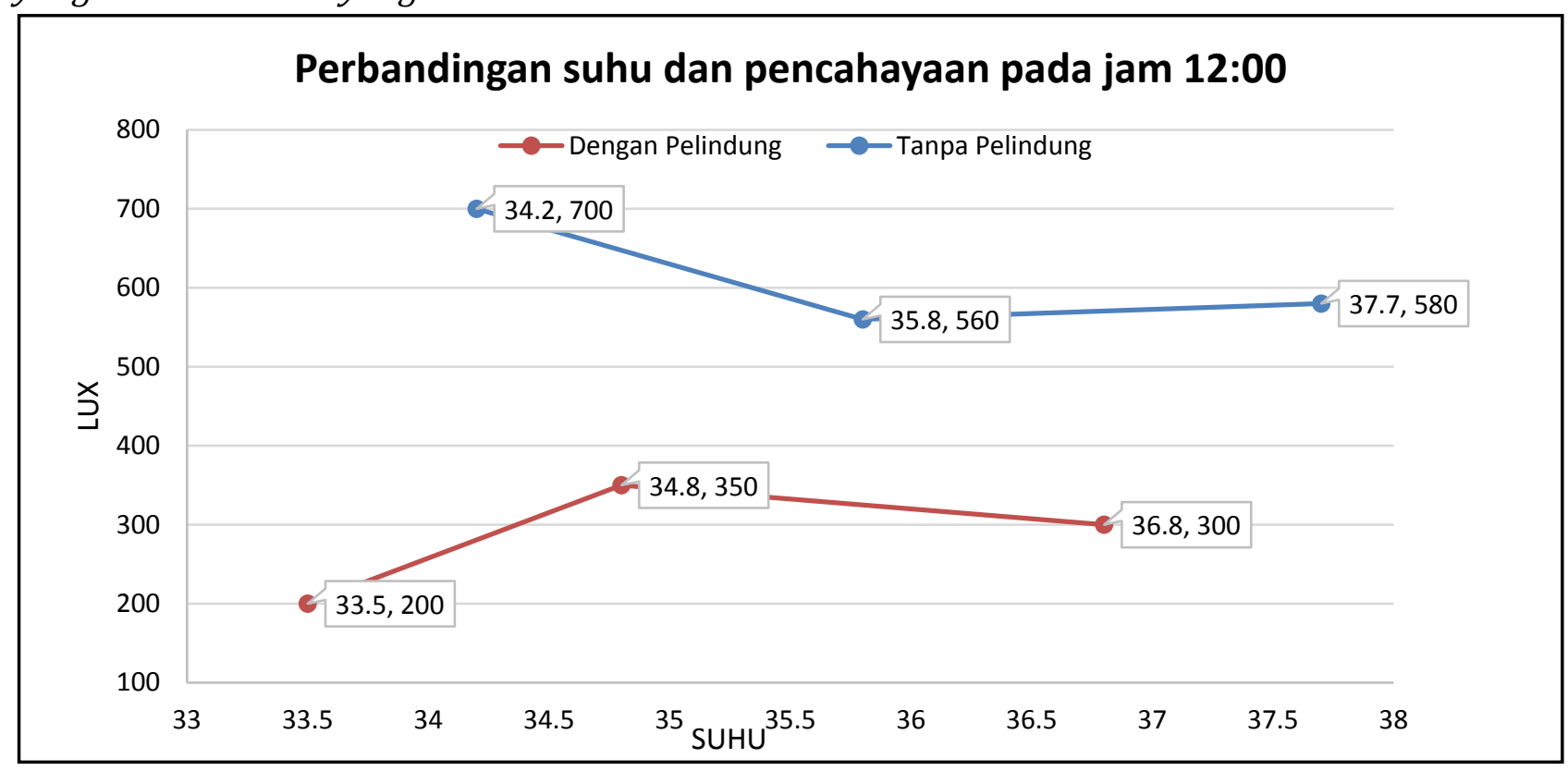

Grafik.6. Perbandingan suhu dan pencahayaan

Pada grafik diatas dapat digambarkan optimasi sudut kemiringan proteksi surya pada sudut $90^{\circ}(\mid), 0^{\circ}(-)$, dan $45^{\circ}(/)$, Berdasarkan temperatur suhu yang diambil pada jam 12.00. Lux yang didapat terpengaruh dari pelindung yang diberikan pada salah satu jendela kaca prototipe. Pada grafik diatas di dapatkan pada bangunan prototipe yang tidak diberikan pelindung memiliki nilai yang tinggi dibandingkan dengan bangunan prototipe yang di pasangkan pelindung pada bagian kaca jendela. Pada grafik di atas suhu yang paling tinggi ada pada sudut variasi kemiringan $45^{\circ}(/)$, dimana pada kedua prototipe sama-sama memiliki nilai lebih tinggi dibandiingkan dengan kedua sudut variasi pada jam yang sama dan nilai pencahayaan yang paling tinggi juga dialami sudut variasi kemiringan $0^{\circ}(-)$.

Sehingga bangunan yang dipasangkan pelindung pada kaca jendela lebih baik dalam meminimalkan suhu dan juga Penmcahayaan yang masuk kedalam bangunan prototipe. Dibandingkan dengan bangunan yang tanpa di beri pelindung. Pelindung yang dipasangkan 
pada jendela kaca prototipe terjadi selisih suhu dan penahayaan yang signifikan kerena pelindung yang di pasang pada kaca jendela dengan sudut variasi $90^{\circ}(\mid), 0^{\circ}(-)$, dan $45^{\circ}(/)$ dapat memantulkan pancaran matahari lansung yang akan masuk kedalam ruangan.

Maka nilai suhu dan pencahayaan yang didapatkan dari kedua protoripe lebih tinggi terutama pada rumah yang tidak dipasangkan proteksi surya pada jendela kaca prototipe. Dimana pelindung yang dipasang berfungsi memantulpan sinar matahari yang masuk kedalam bangunan, sehinnga suhu dan pencahayaan yang masuk ke dalam banguna prototipe lebih rendah dibandingkan dengan yang tidak di pasangkan proteksi surya.

Jadi dari ketiga variasi sudut pada grafik diatas diambil pada jam 12:00 yang lebih baik dalam menahan suhu panas dan sinar matahari yang masuk kedalam ruangan secara langsung adalah proteksi surya dengan variasi sudut $90^{\circ}$ karena suhu dalam ruangan prototipe yang dipasangkan pelindung kaca jendelanya jauh lebih baik dari pada prototipe bangunan yang tidak diberi pelindung pada jendela kaca.

Selain itu juga mampu memantulakan pancaran sinar matahari yang masuk secara langsung kedalam ruangan tanpa mengurani kenyaman dalam beraktifitas dalam ruangan karena pencahayaan yang dihasilkan terbilang baik dalam melakukan kegiatan dalam ruangan pada pagui hari, tanpa menggunakan pencahayaan buatan tambahan dari lampu.

Perbandingan suhu dan pencahayaan pada jam 14:00, Pengambilan data dilakuka pada jam yang sama dan hari yang berbeda.

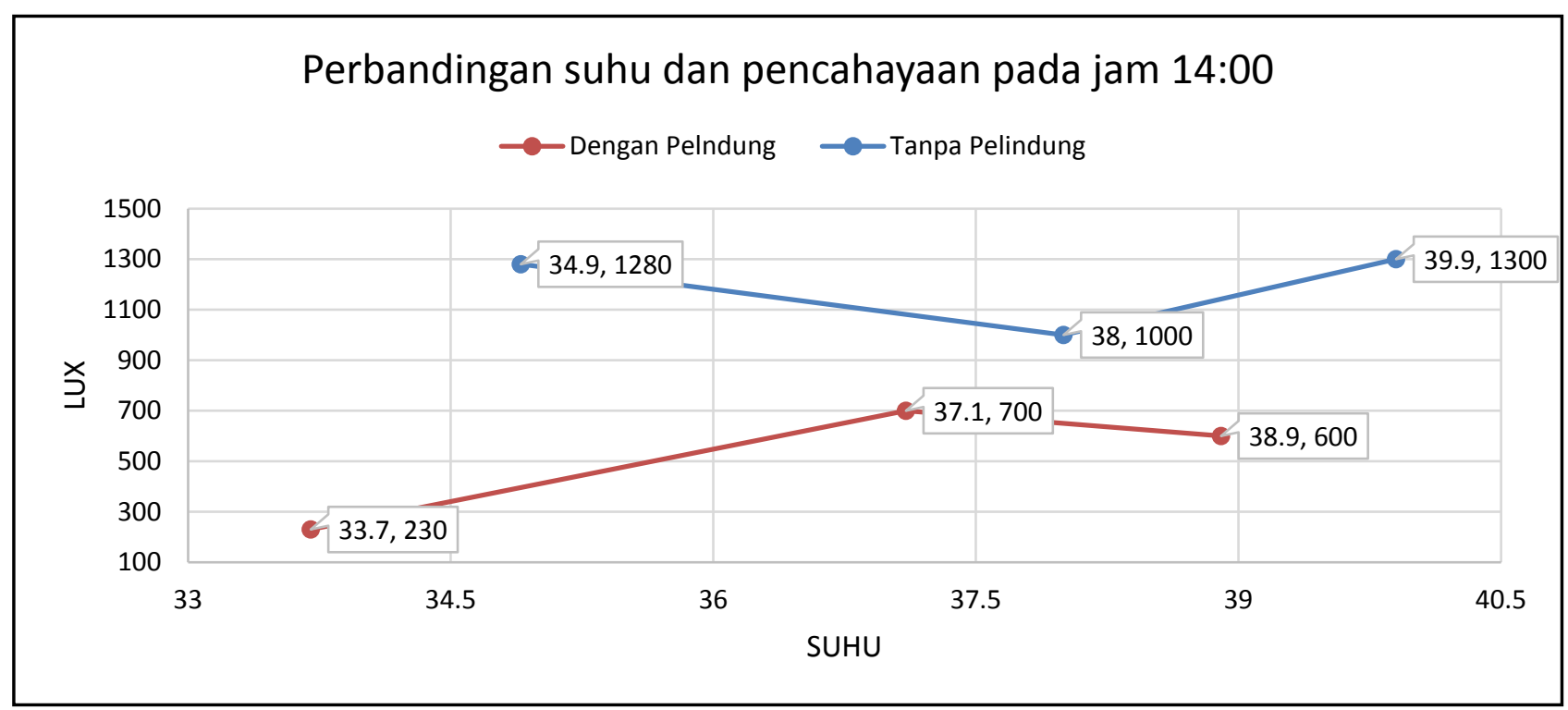

Grafik.7. Perbandingan suhu dan pencahayaan

Pada grafik diatas dapat digambarkan optimasi sudut kemiringan proteksi surya pada sudut $90^{\circ}(\mid), 0^{\circ}(-)$, dan $45^{\circ}(/)$, Berdasarkan temperatur suhu yang diambil pada jam 14.00. Lux yang didapat terpengaruh dari pelindung yang diberikan pada salah satu jendela kaca prototipe. Pada grafik diatas di dapatkan pada bangunan prototipe yang tidak diberikan pelindung memiliki nilai yang tinggi dibandingkan dengan bangunan prototipe yang di pasangkan pelindung pada bagian kaca jendela. Pada grafik di atas suhu yang paling tinggi ada pada sudut variasi kemiringan $45^{\circ}(/)$, dimana pada kedua prototipe sama-sama memiliki nilai lebih tinggi dibandiingkan dengan kedua sudut variasi pada jam yang sama dan nilai pencahayaan yang paling tinggi juga dialami sudut variasi kemiringan $0^{\circ}(-)$.

Sehingga bangunan yang dipasangkan pelindung pada kaca jendela lebih baik dalam meminimalkan suhu dan juga Penmcahayaan yang masuk kedalam bangunan prototipe. 
Dibandingkan dengan bangunan yang tanpa di beri pelindung. Pelindung yang dipasangkan pada jendela kaca prototipe terjadi selisih suhu dan penahayaan yang signifikan kerena pelindung yang di pasang pada kaca jendela dengan sudut variasi $90^{\circ}(\mid), 0^{\circ}(-)$, dan $45^{\circ}(/)$ dapat memantulkan pancaran matahari lansung yang akan masuk kedalam ruangan.

Maka nilai suhu dan pencahayaan yang didapatkan dari kedua protoripe lebih tinggi terutama pada rumah yang tidak dipasangkan proteksi surya pada jendela kaca prototipe. Dimana pelindung yang dipasang berfungsi memantulpan sinar matahari yang masuk kedalam bangunan, sehinnga suhu dan pencahayaan yang masuk ke dalam banguna prototipe lebih rendah dibandingkan dengan yang tidak di pasangkan proteksi surya.

Jadi dari ketiga variasi sudut pada grafik diatas diambil pada jam 12:00 yang lebih baik dalam menahan suhu panas dan sinar matahari yang masuk kedalam ruangan secara langsung adalah proteksi surya dengan variasi sudut $90^{\circ}$ karena suhu dalam ruangan prototipe yang dipasangkan pelindung kaca jendelanya jauh lebih baik dari pada prototipe bangunan yang tidak diberi pelindung pada jendela kaca.

Selain itu juga mampu memantulakan pancaran sinar matahari yang masuk secara langsung kedalam ruangan tanpa mengurani kenyaman dalam beraktifitas dalam ruangan karena pencahayaan yang dihasilkan terbilang baik dalam melakukan kegiatan dalam ruangan pada pagui hari, tanpa menggunakan pencahayaan buatan tambahan dari lampu

\section{SIMPULAN DAN SARAN}

\section{Simpulan}

Jenis pelindung jendela bangunan yang memiliki kenyamanan ruangan pada siang hari baik adalah bangunan yang di pasangkan proteksi surya, karena pada siang hari bangunan terasa sejuk. Sedangkan untuk kaca jendela bangunan yang tidak menggunakan pada siang hari kenyaman ruangan sangat panas.

Kemampuan proteksi surya bagus dalam menahan panas yang masuk kedalam bangunan rumah, dimana pada saat matahari mengenai jendela kaca maka panas tersebut dipantulkan keluar dan tidak di transfer langsung ke dalam ruangan. Jendela kaca yang tidak di beri pelindung dalam menahan panas sangat buruk, karena pada saat matahari mengenai langsung bagian jendela kaca maka panas tersebut langsung ditransfer kedalam ruangan.

Bangunan yang dipasangkan proteksi surya pada jendela kaca efektif dalam meminimalkan panas yang masuk ke dalam ruangan bangunan, Sedangkan yang tidak di pasangkan pada bagian jendela kaca, antara panas yang diterima dan panas yang masuk keruangan adalah sama.

\section{Saran}

Dalam perancangan dan pembuatan prototipe dengan beberapa material pelindung kaca jendela banguna ini, demi upaya pengurangan penggunaan konsumsi listrik, ada beberapa saran yang ingin penulis sampaikan. Pertama, untuk penelitian selanjutnya perancangan dan pembuatan prototipe sebaiknya menggunakan skala yang tidak terlalu jauh dari ukuran sebenarnya, sehingga pada saat pengujian hasilnya tidak terlalu jauh dari yang diharapkan. Kemudian dalam melakukan pengujian sebaiknya memperhatikan letak sensor suhu setiap saat agar tetap berada diposisi semula, sehingga hasilnyapun maksimal. Lalu pada saat pengujian carilah cuaca yang paling bagus, karena perubahan cuaca dapat mempengaruhi hasil. Dan terakhir, hasil penelitian yang dilakukan masih belum memenuhi kriteria nyaman, untuk itu disarankan untuk penelitian selanjutnya agar memilih jenis pelindung kaca jendela lainnya yang dapat memenuhi kriteria nyaman untuk wilayah yang beriklim tropis. 


\section{DAFTAR RUJUKAN}

[1] Akbari, H. et al (1990), Summer Heat Island, Urban Trees and White Surfaces, ASHRAE Transactions, pp. 1381 - 1388.

[2] Anonymous (1989), Handbook of Fundamental, Chapter 8: Physiological Principles, Comfort and Health, ASHRAE, USA.

[3] ANSI/ASHRAE 55-1992, ASHRAE Standard Thermal Environmenttal Conditions for Human Occupancy, American Society of Heating Refrigeration and Air Conditioning Engineer (ASHRAE), Atlanta USA.

[4] Basaria, Talarosha. 2005. Menciptakan Kenyamanan Termal Bangunan. Jurnal Sistem Teknik Industri, 6(3).

[5] Buku Pedoman Penulisan Karya Ilmiah Skripsi/Tugas Akhir dan Proyek Akhir. (2015). Padang: FT UNP.

[6] Departemen Pekerjaan Umum (1993), Standar: Tata Cara Perencanaan Teknis Konservasi Energi Pada Bangunan Gedung, Bandung: Yayasan LPMB.

[7] IEA (International Eergy Agency). 2000. Daylight in Bildings; A Source Book on Daylighting Systems and Components. The Lawrence Berkeley National Library: California.

[8] ISO 7730:1994 (E), Moderate Thermal Environments-Determination of the PMV and PPD Indices and Specification of the Conditions for Thermal Comfort, 2nd edition, 1994, International Organization for Standardization, Geneva, Switzerland.

[9] Jimi Harto Saputro, Tejo Sukmadi dan Kartono, 2013, Analisis Penggunaan Lampu LED Pada Penerangan Dalam Rumah

[10] Karyono, T.H. (1996), Thermal Comfort in the Tropical South East Asia Region, Architectural Science Review, vol. 39, no. 3, pp. 135- 139, Sydney, Australia.

[11] Karyono, T.H. (1997), Arsitektur Tropis dan Bangunan Hemat Energi, majalah KALANG, no1, vol.1, 1997

[12] Karyono, T.H. (2001), Teori dan Acuan Kenyamanan Termis dalam Arsitektur, Catur Libra Optima, Jakarta.

[13] Karyono, T.H. 2001. "Penelitian Kenyamanan Termis di Jakarta sebagai Acuan Suhu Nyaman Manusia di Indonesia." Jurnal Teknik Arsitektur, Fakultas Teknik Sipil dan Perencanaan Universitas Petra. 29(1).

[14] Kerr, Thor. 2008. The Green Future of Buildings. Futurarc Magazine, 3rd quarter, volume 10. Jakarta: PT BCI Asia Construction Information Pte Ltd

[15] Kreit, F (alih bahasa Arko Prijono). 1991. Prinsip-prinsip Perpindahan Panas. Jakarta: Erlangga.

[16] Lechner Norbert. 2007 Heating, Cooling, Lighting, Design Method for Architects, Jakarta; PT.Rajagrafindo Persada

[17] Lippsmeier, Georg (1994), Tropenbau Building in the Tropics, Bangunan Tropis (terj.), Jakarta: Erlangga.

[18] Loekita, S., 2006. Analisis Konservasi Energi Melalui Selubung Bangunan. Civil Engineering Dimension, 8(2), pp.93-98.

[19] Mangunwijaya, Y.B., (1988), Pengantar Fisika Bangunan, Jakarta: Djambatan

[20] Nicol, F.J. (1993), Thermal Comfort A Handbook for Field Studies toward an Adaptive Model, University of East London, UK.

[21] Paulus Sukusno, Sri Wardani 2011,"Analisis Konsumsi Energi Listrik Pada Berbagai Jenis Lampu dan Komputer Untuk Acuan Dalam Audit Energi" Politeknologi Vol 10 No, 3, September 2011,

[22] Prakoso, N.A., Lamahala, A.K. \& Sentanu, G., 2014. Kajian Penerapan Material pada Selubung Bangunan yang Mempengaruhi Kenyamanan Termal dan Visual. Reka Karsa, 2(2), pp.1-12. 
[23] Putra, I dewa Gede Agung Diasan, 2012,"Perencanaan Pencahayaan Buatan Pada interior ruang kelas.

[24] Rilatupa, J. 2008. “Aspek kenyamanan termal pada pengkondisian ruang dalam”. EMAS Jurnal Sains dan Teknologi, 18(3), 191-198.

[25] Roaf, Sue, Manuel Fuentes (2001), Ecohouse, A Design Guide, Oxford: Architectural Press.

[26] Satwiko, Prasato. 2004. Fisika Bangunan 2. Edisi Pertama. Yogyakarta: Andi.

[27] Soegijanto, 1999. Bangunan di Indonesia dengan Iklim Tropis Lembab Ditinjau dari Aspek Fisika Bangunan, Jakarta: Direktorat Jenderal Pendidikan Tinggi Departemen Pendidikan dan Kebudayaan Republik Indonesia.

[28] Supribadi. 1993. Ilmu Bangunan Gedung, Penerbit: CV. Amrico Bandung

[29] Szokolay S.V, et. al (1973), Manual of Tropical Housing and Building, Bombay: Orient Langman.

[30] Szokolay, S.V., Arvind Krishan, Nick Baker, dan Simon Yannas. 2001. Climate Responsive Architecture; A Design handbook for Energy Efficient Building. New Delhi: Tata McGrawHill Publishing Co.Ltd

[31] Talarosha, B. 2005. "Menciptakan kenyamanan thermal dalam bangunan". Jurnal Sistem Teknik Industri". 6(3). 